\title{
The Effect of Plan Type and Comprehensive Medication Reviews on High-Risk Medication Use
}

\author{
Armando Silva Almodovar, PharmD; David Rhys Axon, MPharm, MS; \\ Ashley M. Coleman, PharmD; Terri Warholak, PhD; and Milap C. Nahata, MS, PharmD
}

\begin{abstract}
BACKGROUND: In 2007, the Centers for Medicare \& Medicaid Services (CMS) instituted a star rating system using performance outcome measures to assess Medicare Advantage Prescription Drug (MAPD) and Prescription Drug Plan (PDP) providers.

OBJECTIVE: To assess the relationship between 2 performance outcome measures for Medicare insurance providers, comprehensive medication reviews (CMRs), and high-risk medication use.

METHODS: This cross-sectional study included Medicare Part C and Part D performance data from the 2014 and 2015 calendar years. Performance data were downloaded per Medicare contract from the CMS. We matched Medicare insurance provider performance data with the enrollment data of each contract. Mann Whitney U and Spearman rho tests and a hierarchical linear regression model assessed the relationship between provider characteristics, high-risk medication use, and CMR completion rate outcome measures.
\end{abstract}

RESULTS: In 2014, an inverse correlation between CMR completion rate and high-risk medication use was identified among MAPD plan providers. This relationship was further strengthened in 2015. No correlation was detected between the CMR completion rate and high-risk medication use among PDP plan providers in either year. A multivariate regression found an inverse association with high-risk medication use among MAPD plan providers in comparison with PDP plan providers in 2014 (beta $=-0.358$, $P<0.001$ ) and 2015 (beta $=-0.350, P<0.001$ ), the CMR completion rate in 2015 (beta $=-0.221, P<0.001$ ), and enrollee population size in 2015 (beta $=-0.203, P=0.001$ ).

CONCLUSIONS: This study found that MAPD plan providers and higher CMR completion rates were associated with lower use of high-risk medications among beneficiaries.

J Manag Care Spec Pharm. 2018;24(5):416-22

Copyright $\odot 2018$, Academy of Managed Care Pharmacy. All rights reserved.

\section{What is already known about this subject}

Previous research has shown the positive effect of comprehensive medication reviews (CMRs) on high-risk medication use.

High-risk medication use is associated with an increased risk for confusion, falls, and mortality among older adults.

\section{What this study adds}

This study evaluated the association between CMR completion rates and high-risk medication use among Medicare Part C and Part D performance measures.

Study results showed that Medicare Advantage insurance providers and higher CMR completion rates were associated with lower high-risk medication use.

I n 2007, the Centers for Medicare \& Medicaid Services (CMS) instituted a 5-point star rating system to assess the quality and efficacy of services provided by Medicare plan providers. ${ }^{1}$ This performance metric broadly constitutes 5 categories: quality of access, processing, outcomes, intermediate outcomes, and patient experience. ${ }^{2}$ The overall star rating was determined by a weighted, aggregate score composed of up to 47 quality and performance outcome measures. ${ }^{3,4}$ This rating is used to evaluate the performance of Medicare Advantage Prescription Drug (MAPD) and Prescription Drug Plan (PDP) providers. ${ }^{1}$ MAPD providers that scored less than a 3-star summary rating for 3 consecutive years are subject to termination. ${ }^{5}$ In addition, passage of the 2010 Affordable Care Act permitted CMS to incentivize high-performing (e.g., 4 or more stars) MAPD providers with quality bonus payments. ${ }^{1}$ In 2012, the intermediate and full outcome performance measures were triple weighted. ${ }^{1}$ Improvement in these measures may significantly improve an insurance provider's star rating and effect its ability to receive bonus payments in the following year.

Adults aged over 65 years are particularly susceptible to the adverse effects of specific medications partly because of physiological changes associated with aging. ${ }^{6}$ These high-risk, or potentially inappropriate, medications are categorized as such because of the increased risk of confusion, falls, and mortality in older adults. ${ }^{7}$ In 1991, the Beers Criteria was published, which explicitly defined inappropriate prescribing of high-risk medications for older adults residing in nursing homes. ${ }^{8}$ This list has undergone several updates by expert panels. In 2006, the National Committee for Quality Assurance adopted these criteria and created a "Use of High-Risk Medications in the Elderly" performance measure in HEDIS. ${ }^{9}$ This measure was endorsed by the Pharmacy Quality Alliance (PQA) and the National Quality Forum and was subsequently adopted by 
TABLE 1 Mann Whitney U Test Comparison of Characteristics and Performance Measures Between MAPD and PDP Providers, 2014-2015

\begin{tabular}{|c|c|c|c|c|c|c|c|c|c|}
\hline \multirow[b]{2}{*}{ Year } & \multirow[b]{2}{*}{$\begin{array}{c}\text { Insurance } \\
\text { Provider Type }\end{array}$} & Plan Age & \multirow[b]{2}{*}{$P$ Value } & Number of Enrollees & \multirow[b]{2}{*}{$P$ Value } & $\begin{array}{c}\text { High-Risk } \\
\text { Medication Use }\end{array}$ & \multirow[b]{2}{*}{$P$ Value } & $\begin{array}{c}\text { CMR } \\
\text { Completion Rate }\end{array}$ & \multirow[b]{2}{*}{$P$ Value } \\
\hline & & $\begin{array}{l}\text { Median ( } 25 \text { th, } \\
\text { 75th percentile) }\end{array}$ & & $\begin{array}{l}\text { Median ( } 25 \text { th, } \\
\text { 75th percentile) }\end{array}$ & & $\begin{array}{l}\text { Median (25th, } \\
\text { 75th percentile) }\end{array}$ & & $\begin{array}{l}\text { Median ( } 25 \text { th, } \\
\text { 75th percentile) }\end{array}$ & \\
\hline \multirow[t]{2}{*}{2014} & MAPD, $n=225$ & $7.0(4.0,9.0)$ & \multirow[t]{2}{*}{0.720} & $6,447.0$ & \multirow[t]{2}{*}{$<0.001$} & $7.0(5.0,9.0)$ & \multirow[t]{2}{*}{$<0.001$} & $28.2(17.6,37.8)$ & \multirow[t]{2}{*}{$<0.001$} \\
\hline & PDP, $n=55$ & $8.0(7.0,8.0)$ & & $\begin{array}{c}56,230.0 \\
(7,059.0-290,070.0)\end{array}$ & & $10.0(9.0,13.0)$ & & $12.5 \quad(6.4,22.8)$ & \\
\hline \multirow[t]{2}{*}{2015} & MAPD, $n=235$ & $7.0(2.0,10.0)$ & \multirow[t]{2}{*}{0.480} & $\begin{array}{c}6,668.0 \\
(1,717.0-18,992.0) \\
\end{array}$ & \multirow[t]{2}{*}{$<0.001$} & $5.0(4.0,7.0)$ & \multirow[t]{2}{*}{$<0.001$} & $44.5(28.8,56.8)$ & \multirow[t]{2}{*}{$<0.001$} \\
\hline & $\mathrm{PDP}, \mathrm{n}=52$ & $9.0(8.0,9.0)$ & & $\begin{array}{c}43,125.0 \\
(7,720.8-290,622.8)\end{array}$ & & $8.5(7.0,10.0)$ & & $23.7(13.0,37.5)$ & \\
\hline
\end{tabular}

$C M R=$ comprehensive medication review; $M A P D=$ Medicare Advantage Prescription Drug; PDP= Prescription Drug Plan.

CMS as an outcome performance measure to evaluate Medicare providers. ${ }^{9}$

Insurance providers may choose to incorporate several programs and services to improve the use of medications among their enrollee population. One such service, medication therapy management (MTM), offers comprehensive medication reviews (CMRs) whereby a health care practitioner assesses a patient's medication regimen for appropriateness, efficacy, safety, and adherence..$^{10}$ The goal of these services is to optimize a patient's medication regimen, improve early identification of adverse effects and interactions, improve adherence, and enhance patient health-related outcomes. ${ }^{10}$

Cook et al. (2012) found that patients using high-risk medications were more likely to discuss with their physicians recommendations made during a CMR, which resulted in positive medication changes. ${ }^{11}$ Caffiero et al. (2017) observed that interventions made through an MTM program in an integrated health care delivery system reduced use of medications known to increase fall risk in older adults. ${ }^{12}$ Lin et al. (2017) reported that an MTM pharmacist-physician collaboration program focused on improving inappropriate medication use led to significant cost savings. ${ }^{13}$ Moga et. al. (2017) found that a targeted MTM intervention program reduced use of anticholinergic medications among older adults. ${ }^{14}$

In 2016, CMS introduced the CMR completion rate as a Medicare Part D performance measure. ${ }^{3}$ In the context of high-risk medication use, CMRs are expected to mitigate use of potentially inappropriate medications among older adults. Although previous research has detailed the effect of MTM interventions on the reduction of inappropriate medication use in various health care settings, to our knowledge no published studies exist that evaluate the relationship between CMR completion rate and high-risk medication use performance measures. The purpose of this study was to evaluate the relationship between CMR completion rates and high-risk medication use among MAPD and PDP plan providers.

\section{Methods}

This was a cross-sectional study that evaluated CMS performance outcome measures for the 2014 and 2015 calendar years. The CMS performance measures reported for 2016 and 2017 were based on insurance provider performance during 2014 and 2015 calendar years, respectively. ${ }^{3,4}$ Medicare insurance providers were excluded if they were unable to report a CMR completion rate or if they provided only Medicare Part C services to any portion of their population. These datasets included the contract ID, type of organization, and reported score of each performance measure. ${ }^{15,16}$ A separate dataset downloaded from CMS included the enrollee population, if the Medicare provider offered Medicare Part D services, and the start date for the Medicare contract. ${ }^{17}$ These data were downloaded for the 2014 and 2015 calendar years. ${ }^{17}$ The specific measures assessed included high-risk medication use and CMR completion rate. ${ }^{3,4}$ The high-risk medication use measure represents the number of member-years of enrolled beneficiaries aged over 65 years to have received 2 or more prescription fills for the same high-risk prescription medication divided by the number of member-years over 65 years enrolled during the period measured. ${ }^{3,4}$ The high-risk medications used were based on recommendations by the American Geriatric Society and adapted by the PQA., ${ }^{3,4}$ The CMR completion rate represented beneficiaries who received a CMR divided by beneficiaries enrolled in a MTM program for more than 60 days in the qualifying year. ${ }^{3,4}$

The insurance provider information and respective CMS performance outcome measures were coded and entered in IBM SPSS Statistics version 24 (IBM, Armonk, NY). Data were tested for normality using the Wilk-Shapiro test. A Mann Whitney U test was used to evaluate whether statistically significant differences existed between MAPD and PDP providers (Table 1) and was also used to test if there were statistically significant changes between the 2014 and 2015 performance measures of interest (Table 2). A Spearman rho correlation 
The Effect of Plan Type and Comprehensive Medication Reviews on High-Risk Medication Use

\begin{tabular}{|c|c|c|c|c|}
\hline ABL & \multicolumn{4}{|c|}{$\begin{array}{l}\text { Mann Whitney U Test Comparison of } \\
\text { Performance Measures Between } 2014 \\
\text { and } 2015 \text { Among MAPD and PDP } \\
\text { Providers }\end{array}$} \\
\hline $\begin{array}{l}\text { Insurance } \\
\text { Provider Type }\end{array}$ & $\begin{array}{l}\text { Performance } \\
\text { Measure }\end{array}$ & Year & $\mathrm{N}$ & $P$ Value \\
\hline \multirow[t]{4}{*}{ MAPD } & \multirow{2}{*}{$\begin{array}{l}\text { CMR completion } \\
\text { rate }\end{array}$} & 2014 & 225 & \multirow[t]{2}{*}{$<0.001$} \\
\hline & & 2015 & 235 & \\
\hline & \multirow{2}{*}{$\begin{array}{l}\text { High-risk } \\
\text { medication use }\end{array}$} & 2014 & 225 & \multirow[t]{2}{*}{$<0.001$} \\
\hline & & 2015 & 235 & \\
\hline \multirow[t]{4}{*}{$\overline{\mathrm{PDP}}$} & \multirow{2}{*}{$\begin{array}{l}\text { CMR completion } \\
\text { rate }\end{array}$} & 2014 & 55 & \multirow[t]{2}{*}{$<0.001$} \\
\hline & & 2015 & 52 & \\
\hline & \multirow{2}{*}{$\begin{array}{l}\text { High-risk } \\
\text { medication use }\end{array}$} & 2014 & 55 & \multirow[t]{2}{*}{0.001} \\
\hline & & 2015 & 52 & \\
\hline
\end{tabular}

$C M R=$ comprehensive medication review; $M A P D=$ Medicare Advantage

Prescription Drug; PDP = Prescription Drug Plan. coefficient was used to evaluate the relationship between the 2014 and 2015 Medicare performance measures. A preliminary analysis was performed to ensure that no violations occurred in the assumption of monotonicity for all Spearman rho tests. Once a relationship was established using the Spearman rho correlation, a hierarchical multivariate linear regression was performed to further assess the relationship between the CMR completion rate and high-risk medication use and control for the enrollee population size, type of Medicare plan provider, and plan age..$^{18-20}$

The dataset did not include region-specific characteristics of insurance providers, socioeconomic differences of enrolled populations, or individual patient characteristics. ${ }^{21-23}$ These variables may affect high-risk medication use..$^{21-23}$ Preliminary analyses were conducted to ensure that no violation of the assumptions of normality, multicollinearity, and homoscedasticity occurred for the linear regression analysis. Data for the performance measures and enrollee population were transformed using a natural logarithmic function for the regression analysis. A two-tailed a priori alpha level of 0.05 was used for all statistical tests. The Ohio State University Institutional Review Board deemed this study as nonhuman subjects research given that the data were publicly available.

\section{Results}

Study data included 1,249 Medicare providers for 2014 (36,627,617 beneficiaries) and 2015 (37,896,378 beneficiaries). Of these providers, 364 were excluded for failing to report a CMR completion rate because they were too recently established, the number of enrollees was too small, or they experienced problems reporting data. An additional 318 MAPD providers were excluded for only providing Medicare Part $C$ services to any portion of their enrollee population. For the 2014 calendar year, 225 MAPD providers representing 3,772,737 patients and 55 PDP providers representing 22,091,495 patients

\section{TABLE 3 Description of Insurance Providers}

\begin{tabular}{|c|c|c|c|}
\hline & & 2014 Contracts & 2015 Contracts \\
\hline & Type of Provider & n (\%) & n (\%) \\
\hline \multirow[t]{6}{*}{ MAPD } & Employer/union & $\begin{array}{ll}4 \quad(1) \\
\end{array}$ & (2) \\
\hline & HMO/HMO-POS & $170 \quad(61)$ & $188 \quad(66)$ \\
\hline & Local PPO & $44 \quad(16)$ & $37 \quad(13)$ \\
\hline & PFFS & $1 \quad(0)$ & $(0)$ \\
\hline & Regional PPO & (2) & (2) \\
\hline & Total & $225 \quad(80)$ & $235 \quad(82)$ \\
\hline$\overline{\mathrm{PDP}}$ & $\begin{array}{l}\text { Prescription Part D } \\
\text { provider }\end{array}$ & $55 \quad(20)$ & $52 \quad(18)$ \\
\hline \multicolumn{2}{|l|}{ Total } & $280(100)$ & $287(100)$ \\
\hline \multicolumn{4}{|c|}{$\begin{array}{l}\text { HMO = health maintenance organization; HMO-POS = health maintenance } \\
\text { organization-point of service; } \mathrm{MAPD}=\text { Medicare Advantage Prescription Drug; } \\
\mathrm{PDP}=\text { Prescription Drug Plan; } \mathrm{PFFS}=\text { private fee for service; } P P O=\text { preferred } \\
\text { provider organization. }\end{array}$} \\
\hline
\end{tabular}

were included in the sample. The 2015 sample included 235 MAPD providers representing 3,662,994 patients and 52 PDP providers representing 22,068,453 patients (Table 3).

The Wilk-Shapiro test indicated non-normal distribution $(<0.05)$. A preliminary test indicated that the performance measures of interest followed a monotonic relationship. Preliminary analyses indicated no violation of the assumptions of normality, multicollinearity and homoscedasticity for the linear regression analysis. A Mann Whitney $U$ test found that PDP providers had significantly more enrollees than MAPD in 2014 and 2015 (Table 1). During the same years, MAPD providers had significantly lower high-risk medication use scores and higher CMR completion rates than PDP providers (Table 1). The high-risk medication use performance measure was significantly lower, and the CMR completion rate was significantly higher among MAPD and PDP providers in 2015 compared with 2014 rates (Table 2).

For MAPD providers in 2014, the Spearman rho correlation indicated an inverse correlation between CMR completion rate and high-risk medication use ( $r h o=-0.144, n=224, P=0.031$ ). This relationship was strengthened in 2015 (rho $=-0.261, \mathrm{n}=234$, $P<0.001$ ), which indicated a small inverse statistically significant relationship between the CMR completion rate and the high-risk medication use performance measure. However, no relationship was detected between the CMR completion rate and high-risk medication use among PDP providers in 2016 (rho $=-0.021$, $\mathrm{n}=55, \mathrm{P}=0.88)$ nor in 2017 (rho $=-0.057, \mathrm{n}=52, \mathrm{P}=0.68)$.

\section{Hierarchical Multiple Regression: 2014}

The number of years that an insurance provider had been in service (plan age), size of enrollee population, and if a provider was an MAPD or PDP plan provider (plan provider type) were entered as step 1 in the hierarchical linear regression, explaining $13.2 \%$ of the variance in high-risk medication use. After entry of the CMR completion rate in step 2, the total variance 


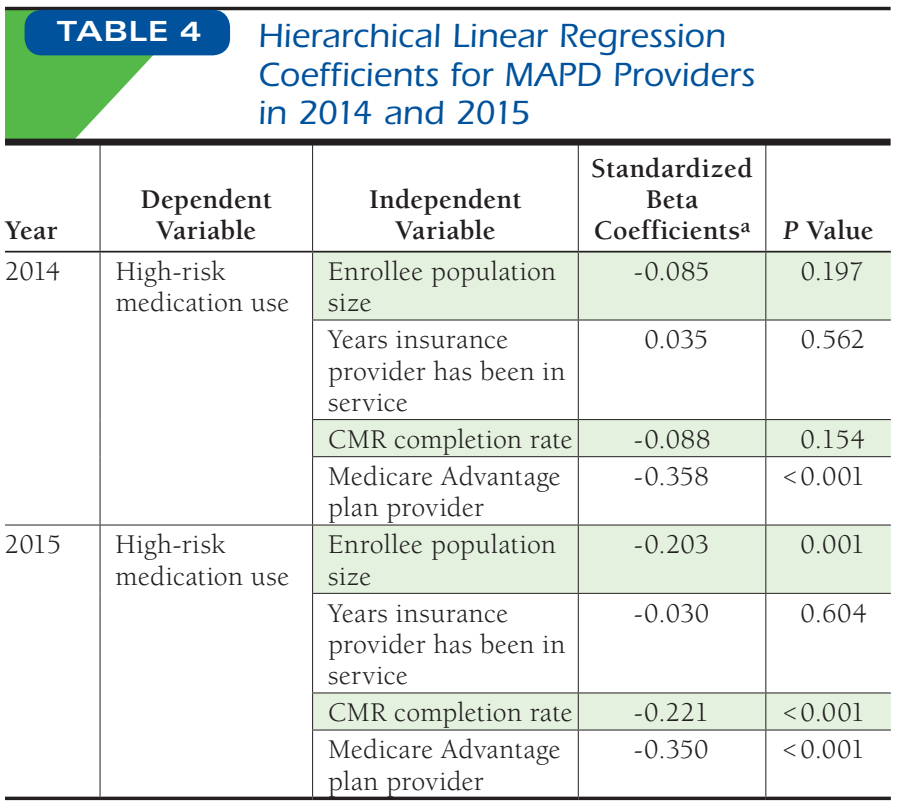

aThe standardized beta coefficient reflects the strength of the effect of an independent variable on a dependent variable. A standard deviation change of 1 in the independent variable will result in a standard deviation change in the dependent variable equal to the standardized beta coefficient, assuming other variables remain constant.

$C M R=$ comprehensive medication review; $M A P D=$ Medicare Advantage Prescription Drug.

explained by the model was $13.8 \%$ (F change $[4,274]=10.97$, $P<0.001)$. The addition of the CMR completion rate explained an additional $0.6 \%$ of the variance in high-risk medication use after controlling for plan age, size, and type of Medicare plan provider ( $R$ squared change $=0.006, F$ change $[1,274]$, $P=0.154)$. In the final model, only type of Medicare plan provider (beta $=-0.335, P<0.001$ ) was statistically significant and inversely correlated with high-risk medication use (Table 4). These data suggest that MAPD providers are associated with a decrease of 0.34 standard deviations in the high-risk medication use performance measure when compared with PDP providers, assuming that all other variables are constant.

\section{Hierarchical Multiple Regression: 2015}

The plan age, size of enrollee population, and plan provider type were entered as step 1 in the hierarchical linear regression, explaining $16.9 \%$ of the variance in high-risk medication use. After entry of the CMR completion rate in step 2, the total variance explained by the model was $20.7 \%$ (F change $[4,280]=18.27, P<0.001)$. The addition of the CMR completion rate explained an additional $3.8 \%$ of the variance in highrisk medication use after controlling for plan age, size, and type of Medicare plan provider ( $R$ squared change $=0.038$, $F$ change $[1,280], P<0.001)$. In the final model, CMR completion rate (beta $=-0.221, P<0.001)$, Medicare plan provider type (beta $=-0.350, P<0.001$ ), and enrollee population size (beta $=-0.203, P=0.001$ ) were statistically significant and inversely correlated with high-risk medication use (Table 4). These data suggest that MAPD providers are associated with a decrease of 0.35 standard deviations in the high-risk medication use performance measure, assuming all other variables are constant. It also suggests that for every increase by 1 standard deviation in the enrollee population size and the CMR completion rate, there would be a decrease in the high-risk medication use performance measure by 0.20 and 0.22 standard deviations, respectively, assuming that all other variables are constant.

\section{Discussion}

Identification of high-risk medications and substitution with therapeutic alternatives remain the focus of guidelines such as the Beer's Criteria, as well as the Screening Tool of Older Persons' potentially inappropriate Prescriptions (STOPP) in combination with the Screening Tool to Alert doctors to Right Treatment (START) criteria (i.e., STOPP/START). ${ }^{7,24}$ CMRs provide an opportunity for health care practitioners to apply these guidelines to mitigate high-risk medication use among older adults. This study provided evidence that MAPD insurance providers with higher CMR completion rates may significantly decrease the use of high-risk medications among their Medicare-age patient population.

The analysis revealed that MAPD and PDP providers in 2015 had higher CMR completion rates and lower high-risk medication use compared with providers in 2014. These results provide initial evidence that providers made strides in improving these performance measures; however, future research is needed to elucidate what these steps entail. The small inverse correlation between the performance measures among MAPD providers suggests that improvements in CMR completion rate and high-risk medication use were inversely correlated. Also, the increasing strength of the correlation from 2014 to 2015 suggests that higher CMR completion rates are necessary to significantly influence (reduce) high-risk medication use among enrollees at the insurance contract level.

The linear regression results differed from the Spearman rho correlation findings. The CMR completion rate in the linear regression did not significantly influence high-risk medication use among older adults in the 2014 sample. Incongruently, in 2015, the CMR completion rate significantly affected highrisk medication use, along with enrollee size and Medicare Advantage plan provider status. There are 2 potential explanations for this difference between the regression and correlation results. First, in 2014, the small effect size of the CMR completion rate may have been undetectable in the linear regression. Second, the median CMR completion rate was $28.2 \%$ and $12.5 \%$ among MAPD and PDP providers, respectively, in 2014. In 2015, an inverse association was found between the CMR 
completion rate and high-risk medication in the multivariate linear regression, since the median CMR completion rate increased to $44.5 \%$ and $23.7 \%$ among MAPD and PDP plan providers, respectively.

It is important to note that Medicare providers use a specific set of criteria to qualify patients for the receipt of MTM services. Patients are deemed eligible for MTM services once they reach a specific threshold regarding number of qualifying medical conditions, medications, and annual drug costs. ${ }^{25}$ In 2015 , qualification criteria included patients with at least 2-3 qualifying chronic health conditions, a minimum of 2-8 chronic medications, and a minimum annual Medicare Part D drug cost of $\$ 3,138 .{ }^{25}$ These criteria may limit which patients can receive MTM services such as CMRs. However, number of medications is an important risk factor for inappropriate medication use..$^{21,26}$ Although MTM services are limited to a specific population, an inverse association was found between the provision of CMRs and high-risk medication use. Further research is needed to make clear the degree of high-risk medication use between a CMR-eligible population and a noneligible population.

These study findings parallel previous research indicating that older adults who received MTM services were more likely to report discontinuation of their high-risk medications. ${ }^{11}$ It is important to note that, although significant, the linear regression model only explained $20.7 \%$ of the variance in high-risk medication use. There are several potential reasons for this. Xu et al. (2015) found that nonprofit, older plan-age MAPD providers with a large enrollee population were more likely to receive higher star ratings. ${ }^{18}$ Another study found that the provision of targeted medication reviews to identify medication-related problems among CMR-eligible patients may significantly affect the appropriate use of medications among this population. ${ }^{27}$ This finding suggests that provision of targeted medication reviews by insurance providers may have confounded the results of this analysis, given the inability to control for these additional services. Furthermore, it is reasonable to suggest that use of high-risk medications is necessary for managing conditions such as chronic neuropathic pain. ${ }^{28}$ As such, the performance measure did not correct for individual patient characteristics.

Our results showed that the size of an MAPD provider's enrollee population had a significant effect on high-risk medication use. This finding parallels previous research that has shown a positive association between insurance provider enrollee population, performance measures of individual providers, and overall star ratings. ${ }^{18,19}$ This association stands to reason given that insurance providers with higher star ratings benefit from quality bonus payments, which allows them to provide more health care services at lower costs and consequently results in higher enrollment rates. ${ }^{20}$
Among PDP providers, no association between the CMR completion rate and high-risk medication use was detected. This may be attributable to several reasons. PDP providers focus on optimizing access and payment of medications, while MAPD providers take a more holistic view of patient therapy because they are also responsible for the medical costs of the beneficiaries. In addition, PDPs may provide CMRs to a smaller percentage of their beneficiaries than MAPD providers, resulting in an insignificant effect on the overall use of high-risk medications. PDP providers are responsible for significantly more patients than MAPD providers and may be unable to provide these services to so many patients (Table 1). Furthermore, PDP providers have lower expectations by CMS in complying with certain performance outcome measures, such as the CMR completion rate, because they will not benefit from savings seen in medical care-related expenditure. The combination of these factors may help explain why CMRs did not have a significant effect on high-risk medication use among PDP providers.

\section{Limitations}

This study has some limitations that need to be considered. Data were limited to Medicare insurance providers who reported a CMR completion rate. Insurance providers that were considered too small or too new were not included, which may have limited the applicability of results to the respective providers. Moreover, study results may not reflect the relationship between measures for MAPD providers who provide only Medicare Part C services (and not Part D) to any portion of their enrollee population. It is also important to note that data used for this study were publicly reported contract data reflecting the performance of Medicare insurance providers, which also may limit the generalizability of the results. Given the limitations of the datasets included, we were unable to control for the variables polypharmacy, gender, race, lower income, worse self-reported health, and living in the southern region of the United States and their association with higher rates of inappropriate medication use. ${ }^{21-23}$ Finally, the percentage of an insurance provider's beneficiaries who received a lower income subsidy was negatively associated with the performance of Medicare performance measures. ${ }^{19}$ This specific variable was not evaluated in our study.

\section{Conclusions}

High-risk medication use among adults aged over 65 years remains an important challenge in medical care. This study found that MAPD providers with higher CMR completion rates had lower high-risk medication use. The CMR completion rate performance measure was found to be inversely associated with the high-risk medication use performance measure. 


\section{Authors}

ARMANDO SILVA ALMODOVAR, PharmD; ASHLEY M COLEMAN, PharmD; and MILAP C. NAHATA, MS, PharmD, Ohio State University College of Pharmacy, Columbus. TERRI WARHOLAK, PhD, and DAVID RHYS AXON, MPharm, MS, University of Arizona College of Pharmacy, Tucson.

AUTHOR CORRESPONDENCE: Milap C. Nahata, MS, PharmD, College of Pharmacy, Ohio State University, 500 W. 12th Ave., Columbus, OH 43210. Tel.: 614.292.2472; E-mail: Nahata.1@osu.edu.

\section{DISCLOSURES}

No outside funding supported this study. Silva Almodovar reports a fellowship funded by SinfoniaRx, Tucson, Arizona, during the time of this study. The other authors have nothing to disclose.

\section{ACKNOWLEDGMENTS}

The authors recognize and thank Ann Taylor of the University of Arizona College of Pharmacy for her significant editorial contributions.

\section{REFERENCES}

1. Academy of Managed Care Pharmacy, American Pharmacists Association. Medicare star ratings: stakeholder proceedings on community pharmacy and managed care partnerships in quality. J Am Pharm Assoc (2003). 2014;54(3):228-40.

2. Centers for Medicare \& Medicaid. Fact sheet - 2017 star ratings. In: 2017 star rating and display measures. 2017. Available at: https://www.cms.gov/ medicare/prescription-drug-coverage/prescriptiondrugcovgenin/performancedata.html. Accessed March 31, 2018.

3. Centers for Medicare \& Medicaid Services. Medicare 2016 Part C \& D star rating technical notes. In: 2016 star ratings and display measures. March 24, 2017. Available at: https://www.cms.gov/Medicare/Prescription-DrugCoverage/PrescriptionDrugCovGenIn/PerformanceData.html. Accessed March 31, 2018.

4. Centers for Medicare \& Medicaid Services. Medicare 2017 Part C \& D star rating technical notes. In: 2017 star rating and display measures. March 24, 2017. Available at: https://www.cms.gov/Medicare/Prescription-DrugCoverage/PrescriptionDrugCovGenIn/PerformanceData.html. Accessed March 31, 2018.

5. Centers for Medicare $\&$ Medicaid Services. Announcement of calendar year (CY) 2017 Medicare Advantage capitation rates and Medicare Advantage and Part D payment policies and final call letter. April 24, 2016. Available at: https://www.cms.gov/Medicare/Health-Plans/MedicareAdvtgSpecRateStats/ Downloads/Announcement2017.pdf. Accessed March 31, 2018.

6. Reisner L. Pharmacological management of persistent pain in older persons. J Pain. 2011;12(3 Suppl 1):S21-29.

7. American Geriatrics Society 2015 Beers Criteria Update Expert Panel. American Geriatrics Society 2015 Updated Beers Criteria for Potentially Inappropriate Medication Use in Older Adults. J Am Geriatr Soc. 2015;63(11):2227-46.

8. Marcum ZA, Hanlon JT. Commentary on the new American Geriatric Society Beers Criteria for Potentially Inappropriate Medication Use in Older Adults. Am J Geriatr Pharmacother. 2012;10(2):151-19.

9. Erickson SC, Leslie RS, Patel BV. Is there an association between the highrisk medication star ratings and member experience CMS star ratings measures? J Manag Care Spec Pharm. 2014;20(11):1129-36. Available at: https:// www.jmcp.org/doi/10.18553/jmcp.2014.20.11.1129.
10. American Pharmacists Association and National Association of Chain Drug Stores Foundation. Medication therapy management in pharmacy practice: core elements of an MTM service model. March 2008. Available at: http://www.pharmacist.com/sites/default/files/files/core_elements_of_an_ mtm_practice.pdf. Accessed March 31, 2018.

11. Cook DM, Moulton PV, Sacks TM, Yang W. Self-reported responses to medication therapy management services for older adults: analysis of a 5-year program. Res Social Adm Pharm. 2012;8(3):217-27.

12. Caffiero N, Delate T, Ehizuelen MD, Vogel K. Effectiveness of a clinical pharmacist medication therapy management program in discontinuation of drugs to avoid in the elderly. J Manag Care Spec Pharm. 2017;23(5):525-31. Available at: https://www.jmcp.org/doi/10.18553/jmcp.2017.23.5.525.

13. Lin HW, Lin CH, Chang CK, et al. Economic outcomes of pharmacistphysician medication therapy management for polypharmacy elderly: a prospective, randomized, controlled trial. J Formos Med Assoc. 2018;117(3):235-43.

14. Moga DC, Abner EL, Rigsby DN, et al. Optimizing medication appropriateness in older adults: a randomized clinical interventional trial to decrease anticholinergic burden. Alzheimers Res Ther. 2017;9(1):36.

15. Centers for Medicare \& Medicaid Services. 2016 Medicare report card master table. October 2, 2015. In: 2016 star ratings and display measures. April 10, 2018. Available at: https://www.cms.gov/medicare/prescriptiondrug-coverage/prescriptiondrugcovgenin/performancedata.html. Accessed April 11, 2018.

16. Centers for Medicare \& Medicaid Services. 2017 Medicare report card master table. October 26, 2016. In: 2017 star ratings and display measures. April 10, 2018. Available at: https://www.cms.gov/medicare/prescriptiondrug-coverage/prescriptiondrugcovgenin/performancedata.html. Accessed April 11, 2018.

17. Centers for Medicare \& Medicaid Services. Monthly enrollment by contract. March 15, 2017. Available at: https://www.cms.gov/ Research-Statistics-Data-and-Systems/Statistics-Trends-and-Reports/ MCRAdvPartDEnrolData/Monthly-Enrollment-by-Contract.html?DLSort=1\&D LEntries $=10 \& D L P a g e=2 \& D L S o r t D i r=$ descending. Accessed March 31, 2018.

18. Xu P, Burgess JF Jr, Cabral H, Soria-Saucedo R, Kazis LE. Relationships between Medicare Advantage contract characteristics and quality-of-care ratings: an observational analysis of Medicare Advantage star ratings. Ann Intern Med. 2015;162(5):353-58.

19. Ta JT, Erickson SC, Qiu WA, Patel BV. Is there a relationship between Part D medication adherence and Part C intermediate outcomes star ratings measures? J Manag Care Spec Pharm. 2016;22(7):787-95. Available at: https:// www.jmcp.org/doi/10.18553/jmcp.2016.22.7.787.

20. Li P, Doshi JA. Impact of Medicare Advantage prescription drug plan star ratings on enrollment before and after implementation of quality-related bonus payments in 2012. PLoS One. 2016;11(5):e0154357.

21. Guaraldo L, Cano FG, Damasceno GS, Rozenfeld S. Inappropriate medication use among the elderly: a systematic review of administrative databases. BMC Geriatr. 2011;11:79.

22. Qato DM, Trivedi AN. Receipt of high-risk medications among elderly enrollees in Medicare Advantage plans. J Gen Intern Med. 2013;28(4):546-53.

23. Cooper AL, Dore DD, Kazis LE, Mor V, Trivedi AN. Predictors of highrisk prescribing among elderly Medicare Advantage beneficiaries. Am J Manag Care. 2014;20(10):e469-78.

24. O'Mahony D, O'Sullivan D, Byrne S, O'Connor MN, Ryan C, Gallagher P. STOPP/START criteria for potentially inappropriate prescribing in older people: version 2. Age Ageing. 2015;44(2):213-18.

25. Shapiro JR. CY 2015 medication therapy management program guidance and submission instructions. Memo. May 7, 2014. Available at: https://www. cms.gov/Medicare/Prescription-Drug-Coverage/PrescriptionDrugCovContra/ Downloads/emoContractYear2015MedicationTherapyManagementProgramSubmission050714.pdf. Accessed March 31, 2018. 
26. Mannucci PM, Nobili A; REPOSI Investigators. Multimorbidity and polypharmacy in the elderly: lessons from REPOSI. Intern Emerg Med. 2014;9(7):723-34.

27. Buhl A, Augustine J, Taylor AM, Martin R, Warholak TL. Positive medication changes resulting from comprehensive and noncomprehensive medication reviews in a Medicare Part D population. J Manag Care Spec

Pharm. 2017;23(3):388-94. Available at: https://www.jmcp.org/doi/10.18553/ jmcp.2017.23.3.388.
28. Agency Medical Directors Group. Interagency guideline on prescribing opioids for pain. June 2015. Available at: http://www.agencymeddirectors. wa.gov/Files/2015AMDGOpioidGuideline.pdf. Accessed March 31, 2018. 